MEFFESOLI, Michel. $A$ dinâmica da violência. São Paulo, Vértice, 1987.

MOTTA, Dilson \& MISSE, Michel. Crime o social pela culatra. Rio de Janeiro Achiamé, 1979.

RONDELLI, Elizabeth. "As imagens da violência"

\section{OUTRAS FONTES}

ABREU, Patrícia de. "Ver para crer" in Jornal do Brasil (coluna Ancora). 16/06/2000.
KRAMER, Dora. "Erro de pessoa" in Jornal do Brasil (coluna Coisas da política). 17/ 06/2000.

Revista Veja. São Paulo, Abril. Número 1654 - 21 de junho de 2000.

Revista Istoé. São Paulo, editora Três. Número 1603 - 21 de junho de 2000.

WWW.GLOBO.COM do dia 12 de junho de 2000.

Discursos de Anthony Garotinho e Fernando Henrique Cardoso no 53. Congresso de Jornais, realizado no Rio de Janeiro entre 10 e 14 de junho de 2000 .

\title{
O Projeto que Institui o Novo Código Civil Brasileiro
}

\author{
Carlos Silveira Moronha \\ Professor Titular de Direito Civil da UFRGS \\ Doutor em Direito pela USP
}

1 rans vigência, no Brasil, das Ordenações Fili pinas, promulgadas pelo Reino de Portugal em 1.603, os estudos para a edição de uma codificação nacional própria, destinada a reger as relaçōes civis, tiveram início com o anteprojeto Teixeira de Freitas a cerca de cento e cinqüenta anos, em 1859. Sucederam-no mais quatro tentativas de codificação (Nabuco de Araújo, em 1872; Felicio dos Santos, em 1881; Coelho Rodrigues, em 1893), que desaguaram no anteprojeto Clóvis Beviláqua, editando-se, com a aprovação deste, o atual Código, com a Lei no ${ }^{\circ} .071$, de $1^{\circ}$ de janeiro de 1916 , que vem regendo a vida da Nação a partir de $1^{\circ}$ de janeiro de 1.917.

Embora sem seguir exatamente a sua estrutura sistemática, a codificação civil moderna que mais influenciou o primeiro estatuto nacional foi a inaugurada com o Código Napoleão, de 1.804. O Código Civil Brasileiro de 1.916, tem sua estrutura sistemática composta de uma Parte Geral, dividida em três livros (pessoas, bens e fatos jurídicos) e de uma Parte Especial, dividida em quatro Livros (na seqüência, Direitos de Família, das Coisas, das Obrigações e das Sucessões). Este notável documento jurídico, complementado e modificado por uma abundante legislação extravagante, regeu com plena eficácia e proficiência as relações privadas dos súditos da Nação por qua- se todo o século XX, até que as profundas, radicais e positivas modificações na cultura política e jurídica pátrias, e bem assim as sensiveis alterações na organização social e no modelo econômico, submetidas, todas, a constante questionamento, não como sinal de crise, senão como indicativo da vitalidade da Nação, passaram a exigir uma profunda mudança na ordem civil.

Daí adveio a necessidade de renovar as instituições civis pátrias, que teve seu marco inicial no Governo João Goulart, por intermédio do seu Ministro da Justiça, João Mangabeira, encarregando o professor Orlando Gomes para elaborar um Projeto de Código Civil e o professor Caio Mário da Silva Pereira para projetar um Código de Obrigações.

Abandonando o critério da dualidade e optando pelo da unificação do direito privado, que teve início, entre nós, por Teixeira de Freitas, seguido por Carlos de Carvalho, Coelho Rodrigues, Inglez de Souza, Lacerda de Almeida e outros, o Governo retirou do Congresso Nacional, em 1966, os dois anteprojetos referidos (Pronunciamento do Senador Josaphat Marinho, Edição do Senado, 1997, págs. 20-21).

Em seguida, foi criada uma Comissão de eminentes juristas, sob a coordenação gera do Professor Miguel Reale, da Universidade de 
São Paulo, para preparar um novo Projeto de Código Civil, abrangendo toda a matéria pertinente à ordem civil e privada, sendo a mesm constituída pelos Professores José Carlos Moreira Alves, Ministro do Supremo Tribunal Federal encarregado de redigir a Parte Geral; Agostinho Arruda Alvim, da PUC - São Paulo, a quem coube a redação do Direito das Obrigações Silvio Marcondes, da U.S.P., encarregado de redigir a parte do Direito de Empresa; Eber Vianna Chamoun, da U.E.R.J. - Rio, a elabo ração da parte referente ao Direito das Coisas Clóvis Veríssimo do Couto e Silva, da U.F.R.G.S., para redigir a parte concernente ao Direito de Família; e Torquato Castro, da Fa culdade do Recife, para projetar a parte do Direito das Sucessões.

Na estrutura sistemática, o Projeto segue, com fidelidade, dois dos principais código modernos, o da Alemanha (BGB) e o de Portugal, estando as matérias concernentes à ordem civil e privada distribuídas em seis Livros, mantida a Parte Geral, seguindo-se, na ordem, a Parte Especial, constituída do Direito das Obrigaçōes, do Direito de Empresa, do Direito da Coisas, do Direito de Família e do Direito das Sucessões.

Na Parte Geral, no Livro I, que trata das pessoas, foi alterado para 18 anos a idade para a aquisição da capacidade civil plena (art $1^{\circ}$ ), introduzindo o Projeto Capítulo próprio para regrar os direitos da personalidade (arts. 11 a 21), bem como foi transferido para esta sede o instituto que trata da ausência, regulan do seus efeitos na sucessão provisória e definitiva (arts. 22 a 39), no sistema anterior disci plinado no Livro do Direito de Família. Quanto às pessoas jurídicas, está delineada a distinção da associações e fundações em relação às sociedades, incluídas no campo das primeiras as de natureza civil, tais as piedosas, religiosas, morais, científicas, culturais, esportivas e de assistênci (arts. 53 a 69), reservando às segundas as de natureza empresarial, com fins lucrativos, comerciais e industriais (arts. 981 a 985). Foi acolhida a despersonalização da pessoa jurídica "disregard doctrine", para responsabilizar os administradores ou sócios da pessoa jurídica por desvio da sua finalidade ou pela confusão patrimonial, caracterizadas como abuso na condução dos seus negócios, quando causadores de prejuízo a terceiros, instituto esse que já vinha sendo adotada na doutrina e na jurisprudência nacionais (art. 50)

Ainda na Parte Geral, no Livro III, que se ocupa dos fatos jurídicos, o Projeto deu ênfase à categoria dos negócios jurídicos, com mais cuidadosa determinação de sua constituição, defeitos e invalidade, estabelecendo aí as regras gerais para a disciplina específica do instituto no âmbito do Direito das Obrigações, de modo a arredar as indeterminações que sobre esse tema grassavam no estatuto anterior (arts. 104 a 137) Nessa sede, contemplou o Projeto o princípio da boa-fé, como cláusula geral destinada a exornar e qualificar de credibilidade aprioristicamente todos os negócios jurídicos. Entre os defeitos que inquinam de invalidade 0 negócio jurídico, foram incluídos no Projeto o estado de perigo (art. 156) e a lesão enorme (art. 157), institutos adotados em outros códigos modernos, salientando-se a presença do último no Código Napoleão (art. $1.118 \mathrm{e}$ arts. $1.774 \mathrm{e}$ segs.), mas sem presença expressa no nosso estatuto anterior. Por critério de exclusão, foram diferenciados os atos jurídicos lícitos dos negócios jurídicos (art. 185) e entre os atos ilícitos, terá agora definição clara e direta o abuso de direito (art. 187), tendo como fonte o artigo 334 do Código de Portugal, bem como o dano moral (art. 186), já acolhido pela Constituição Federal (art. $5^{\circ}, \mathrm{V}$ ) estando a sua reparabilidade regulada no artigo 927 do Projeto, sanando, assim, a omissão do Código atual, no seu artigo 159.

Por fim, dentre as alterações figuradas na Parte Geral do Projeto, consta a que distingue os institutos da prescrição e da decadência, re duzindo os prazos para a ocorrência da primeira e bem assim suprindo a omissão da codificação vigente. Ainda, no Título que regula a prova, está dispensada a autenticação de documentos comprobatórios dos atos jurídicos, salvo se alguém impugnar a sua autenticidade (art. 225).

$\mathrm{Na}$ Parte Especial, Livro I, que rege o Direito das Obrigações, proclama o Projeto a função social do contrato, reconhecendo a liberdade de contratar e repelindo o individualismo ensejado na dinâmica da codificação de 1916 (art. 421), submetendo, todavia, os contratantes ao princípio da probidade, compartilhado com o da boa-fé, acolhido como cláusula geral no artigo 113

O respeito à palavra empenhada foi e continua a ser o fundamento ético da teoria contratual. E de tal modo o foi, no passado, que os romanistas construíram, para justificá-lo, o princípio "pacta sunt servanda". Posteriormente, a majestade do contrato, abrigada nos códigos individualistas, sofreu os influxos das transformações sociais e econômicas, tendo sido abrandada por uma cláusula geral implícita a que se chamou cláusula "rebus sic stantibus", notadamente nos contratos de execução continuada ou diferida, quando a prestação de uma das partes se tornasse excessivamente onerosa, com vantagem desproporcional à outra, estabelecendo desequilíbrio entre o direito dos contratantes em razão de acontecimento extraordinário e imprevisível. Para o Projeto, ocorrendo onerosidade excessiva, poderá o devedor postular, sob este fundamento, a resolução do contrato (arts. 478 a 480 ).

Seguindo na esteira do Código de Defesa do Consumidor (Lei $n^{0} 8.078 / 90$ ), o Projeto resguarda a posição do aderente nos contratos de adesão, não só adotando a interpretação mais favorável ao devedor das cláusulas ambíguas ou contraditórias (art. 423), como também decla- rando nulas as cláusulas que estipulem a renúncia antecipada a direito do aderente (art. 424)

O Projeto alinha no elenco dos contratos nominados várias modalidades contratuais não contempladas na codificação de 1916, mas de uso comum no nosso meio. Tais são o contrato de comissão (arts. 693 a 701), contrato de agência e distribuição (arts. 710 a 721), contrato de corretagem (art. 722 a 729), contrato de transporte (arts. 730 a 756), incluindo nessa categoria a transação (arts. 840 a 850) e o compromisso (arts. 851 a 853), e bem assim, arrolando entre os atos unilaterais o enriquecimento sem causa (arts. 884 a 886 ).

No Livro II, da Parte Especial, está contemplado o Direito de Empresa, que implica revogação da primeira parte do Código Comercial de $1^{\circ}$ de junho de 1850 , unificando o direito das obrigações e praticamente o direito privado. Essa opção da Comissão Elaboradora do Projeto vem sendo considerada um avanço por parte da doutrina, porquanto destaca o comerciante como empresário voltado para a atividade econômica, como o vêm caracterizando os tempos modernos.

Nesta sede, o Projeto define a figura do empresário, substituindo a de comerciante tradicionalmente caracterizada no Código Comercial (art. 966) e a capacidade para exercer a atividade (art. 972). A seguir contempla regula todos os ti pos de sociedade, salvo a por ações, cuida de sua constituição, liquidação (arts. 1.102 a 1.112), transformação, incorporação, fusão e cisão (arts. 1.113 a 1.122) e bem assim a autorização governamental para o seu funcionamento (arts. 1.123 a 1.141), espancando, por fim, a confusão entre empresa e estabelecimento (arts. 1.142 a 1.149). O estudo desse assunto já foi particularizado, com muita propriedade e exatidão, pelo Professor Norberto Costa Caruso Mac Donald, sob o título "O Projeto de Código 
Civil e o Direito Comercial", (in Revista da Fa culdade de Direito da UFRGS, Vol. 16, pp. 139 160, Editơa Síntese, Porto Alegre)

No campo do Direito das Coisas, constante do Livro III, da Parte Especial, o Projeto não traz, no geral, grandes modificações em relação à codificação de 1.916. Todavia, proclamada e elevada à hierarquia de princípio pela Constituição (art. 170, III), a função social da propriedade é posta em relevo pelo Projeto, a estabelecer disposições normativas para torná-l efetiva, seja mediante a modernização de institutos tradicionais no setor, seja criando nova opções que na vida prática venham a se colocar em consonância com as condutas econômcas e sociais, aspiradas pela coletividade nos dia atuais. E na persecução desse objetivo, demonstra o Projeto a preocupação em também preservar o equilíbrio da natureza em geral e, em particular, a pureza das águas e do ar, em prol da vida.

Assim é que a proposta de nova codificação civil conserva, em parte, a posição do estatuto ainda vigente, em relação à desapropriação da propriedade privada por necess dade, utilidade pública ou interesse social, bem como a requisição da mesma, pelo poder pú blico, em caso de "perigo público iminente" (art $1.228, \S 3^{\circ}$ ). É de se salientar, todavia, que relativamente a essa hi pótese de requisição, o Projeto avança demais na limitação ao direito de propriedade, porquanto não está a mesma especificamente autorizada no texto constitucional, que só a permite em caso de estado de sitio (Const., art. 139, VII). Poderá, portanto, ser considerada inconstitucional essa disposição da nova lei civil. Ainda na visão do Projeto poderá o proprietário ser privado da coisa, consistente em extensa área, em razão de posse coletiva, po mais de 5 anos, por considerável número de pessoas, que nela realizem obras e serviços considerados de interesse social e econômico rele vante, mediante justa indenização (art. 1.228, § $4^{\circ}$ e e $\left.5^{o}\right)$. Este último dispositivo do Projeto, no entanto, está em consonância com o princípio constitucional que proclama a função social da propriedade (Constituição, art. 170, III).

$\mathrm{Na}$ esfera infraconstitucional, o Projeto mantém o usucapiâo ordinário o extraordinário, clássicos institutos de fonte romana, reduzindo o prazo do segundo para quinze anos, ou para dez anos, se o possuidor tiver fixado no imóvel a sua moradia habitual ou nele realizado obras de caráter produtivo (art. 1.238 e parágrafo único). Quanto ao usucapião ordinário foi o prazo reduzido para dez anos, ou para cinco, no caso de aquisição onerosa do imóvel usucapiendo, pelo possuidor, ainda que insubsistente a transferência da propriedade no registro imobiliário e observados os demais requisitos que ensejam a diminuição do prazo para implementar o usucapião extraordinário (art. 1.242 e parágrafo único). São mantidos, obviamente, o usucapião rural especial, (art. 1.239) criado pela Constituição (art. 191) bem como o usucapião urbano especial (art. 1.240), também criado pela Lei Maior (art. 183), fundados na posse-trabalho ou possepro-labore e obedecidos os demais requisitos constitucionais exigidos para aquisição desses ti pos de propriedade social. De igual modo, reduzidos foram os prazos para a aquisição de coisa móvel, por usucapião, devendo ser de três anos e de cinco anos, respectivamente para as formas ordinária $\mathrm{e}$ extraordinária (arts. 1.260 e 1.261).

Foi transportado da lei especial (Lei $\mathrm{n}^{-}$ 4591/64) para a nova codificação a disciplina normativa do condomínio edilício (arts. 1.331 a $1.358)$, cominando sanções mais pesadas ao condômino que descumprir as regras reguladoras da convivência condominial (arts. 1.336 1.337 e $\S \S$ ). A par disso, o Projeto limita a $2 \%$ a multa aplicável ao condômino que descumprir a obrigação "propter rem" de pagar em dia as cotas condominiais (art. 1.136, $\S 1^{\circ}$ ).
Ainda no âmbito do Direito das Coisas, o Projeto acolheu o direito de superficie, (arts 1.369 a 1.377), já contemplado em outra codificações modernas, como nos códigos fran cês (art. 553), alemão ( $\S 1.012$ a 1.017), português (arts. 1.524 a 1.542), havendo abandonado o instituto da enfiteuse, obedecida, obviamente, a transitoriedade estabelecida para a extinção parcial da mesma no artigo 49 do Ato da Disposições Constitucionais Transitórias.

No Livro IV, da Parte Especial do Projeto, pertinente ao Direito de Família, é sede em que residem as propostas de mudanças mais profundas da nova codificação, a maio parte delas resultantes do comando do artigo 226 da Constituição Federal. É assim que o Projeto começa a contemplar a família, caracterizada pela comunhão plena de vida, emergente do casamento civil e religioso (arts. 1.511 1.512 ), situando ao lado e similar a ela a entidade familiar, consubstanciada na união estável, de fato, entre o homem e a mulher (art. 1.723) omitindo-se, porém, quanto à entidade familiar monoparental também reconhecida pela Cons tituição Federal (art. 226, § $4^{\circ}$ ). Pela primeira vez, no direito pátrio, é definido, ainda que laconicamente, o concubinato, como a união de fato entre o homem e a mulher que tenham impedimentos para o casamento (art. 1727).

Entre as principais alterações no concerto do Direito de Família figuram as de natureza pessoal, que implicam a igualdade absoluta dos cônjuges, quanto aos direitos e deveres no exercício da sociedade conjugal (art. 1.511) igualdade dos filhos consangüíneos havidos no casamento ou fora dele, em qualquer circunstância, inclusive os adotivos, proibidas quaisquer discriminações, como já proclamavam leis anteriores e agora também a Constituição (art. 227, $\S 6^{\circ}$ ); nova classificação dos impedimentos matrimoniais, extensivos à união estável, em dirimentes públicos ou absolutos (arts. 1.521 e 1.522) e em relativos ou impedientes, caracterizados como causas suspensivas do casamento (arts. 1.523 e 1.524), ambos em harmonia simétrica com regras sobre a invalidade do matrimônio (arts. 1.548 usque 1.564).

Por não se compadecer com a nova realidade social, propõe-se a exclusão da anulação do casamento por anterior defloramento da mulher, ignorado pelo marido, disposição essa ainda presente na codificação em vigor (C. $\mathrm{Ci}$ vil, art. 219, IV), e bem assim a não contemplação do adultério como causa de impedimento para o matrimônio, constante até agora do artigo 183 , VII, da codificação vigente.

As relações de parentesco, na linha colateral, esgotam-se no quarto grau (art. 1.592), posição que está em consonância com o direito sucessório, segundo o qual, na sucessão legítima, o direito de suceder dos colaterais estendese até o quarto grau (art. 1.839), enquanto se projeta ao infinito na linha reta, embora esta situação não se verifique na prática, pela efêmera duração da vida humana.

No que respeita à adoção, o Projeto trata, no Capítulo IV, Subtítulo II, do Livro IV, apenas da adoção plena (arts. 1.618 a 1.629), seguindo as linhas gerais do Estatuto da Crianca e do Adolescente (Lei no 8.069/90, arts. 39 a 52), excluída a adoção simples ou restrita, constante na codificação vigente (C. Civil, arts. 368 a 378). É de registrar-se que, na oportunidade da segunda apreciação do Projeto pelo Senado, em outubro/novembro de 2000 , houve manifestaçōes de Senadores, notadamente por parte do Relator, Senador José Fogaça, de que o instituto da adoção deveria ser retirado da codificação civil e restar regulado exclusivamente pelo ECA. Essa proposição, todavia, não foi aprovada.

O Projeto faz coro com o ECA, permitindo sejam adotantes não só os cônjuges, ma também os conviventes em união estável (arts. 
1.618, parágrafo único e art. 1.622) e, ainda, os concubinos, como faz supor a regra do parágrafo único, do artigo 1.626, naturalmente com maiores cautelas do que as exigidas pelas demais pessoas legitimadas, antes referidas. É reduzida pelo Projeto, para 16 anos, a diferença de idade entre adotante e adotado (art. 1.619). Quanto ao mais, a proposta de nova codificação civil segue as linhas diretivas do ECA.

Relativamente aos efeitos patrimoniais decorrentes do casamento, propõe o Projeto modificaçōes no regime de bens, excluindo o regime dotal e admitindo o regime da participação final nos aqüestos (arts. 1.672 a 1.686), este já adotado por outros sistemas, notadamente o francês (Code Civil, arts. 1.569 a 1.581), mas conserva a nova proposta legislativa a manutenção dos demais regimes tradicionalmente acolhidos na lei pátria. $\dot{E}$ atenuada a rigidez da imutabilidade do regime de bens, com a permissão de sua alteração parcial, em casos específicos, mediante autorização judicial (art. 1.639, $\S 2^{2}$ ), situação que já vinha sendo enfrentada pela jurisprudência, se bem que timidamente.

Ainda no tocante às situações patrimoniais ocorrentes no âmbito do Direito de Familia, o Projeto contemplou o bem de família (arts. 1.711 a 1.722) deslocando-o da sede anterior, na parte geral da codificação vigente (C. Civil, arts. 70 a 73), para o Livro do Direito de Família, que é, segundo boa parte da doutrina, a localização mais adequada para o instituto. Os requisitos para a instituição do bem de família estão modificados quanto à pessoa dos instituidores, podendo-o ser por terceiros, além dos cônjuges (art. 1.711, parágrafo único); quanto ao objeto, deve limitar-se a um terço do patrimônio liquido existente ao tempo da instituição (art. 1.711, "caput"), podendo abranger, além de bem imóvel, também valores mobiliários (arts. 1.712 e 1.713); quanto à forma, pode sê-lo por escritura pública, testamento ou doação, segundo os mesmos dispositivos referidos.
A lei $n^{\circ} 8.009 / 90$ ampliou sobremodo a tutela de outros bens patrimoniais da família sob o enfoque do bem de família, isentando-os de penhora e dispensando, inclusive, as formas exigidas pela codificação civil para a sua instituição, acima referidas. Aprovado o Projeto e mantidas as regras atuais nele contidas, poderão surgir conflitos de interpretação quanto à aplicação da nova codificação ou da lei especial extravagante, anterior àquela.

Tendo em vista que mais de duzentas emendas e subemendas, no Livro do Direito de Família, foram introduzidas pelo Senado e na segunda e última passagem do Projeto pela Câmara dos Deputados, muitas outras alterações sobre o casamento, sua celebração, efeitos e invalidade, e bem assim sobre parentesco, filiação, poder familiar, regime de bens, alimentos, adoção e união estável deixam de ser aqui referidas, devido o caráter sumário deste trabalho.

No Livro V, da Parte Especial, segue o Projeto a tradição do Direito das Sucessões, que está assegurado no artigo $5^{\circ}$, inciso $\mathrm{XXX}$ da nossa Constituição e vem marcando presença em todos os sistemas jurídicos ligados ao bloco europeu-constitucional, considerado tronco da chamada família "Civil law". Situa-se o direito sucessório entre os ramos da civilística que vem experimentando as maiores mutações no andar dos tempos. Mas essas inovações contidas no Livro V, não o são por impulso exclusivo do direito das sucessões, senão que recebem o estimulo de regras gerais e princípios contidos na Parte Geral e na Parte Especial deste Projeto de codificação, não sendo demais afirmar-se que este campo da ordem civil constitui-se no receptáculo assegurador da continuidade do direito de propriedade, e mais ainda, recolhe o direito sucessório toda a sua dinâmica e fundamentação projetadas pelas instituições do direito de família. Destarte, as mudanças que o Projeto traz no âmbito do Direito das Sucessões, mais que inovações "per se" deste ramo, são projeções de outros setores da civilistica moderna. E nessa perspectiva, o Direito das Sucessõe repousa na necessidade de proteger a família o patrimônio que a ela deve permanecer unido, na expressão de MAZEAU (Leçons, tomo IV, p. 01).

Começa o Projeto por regular a situação transitória da herança, abrangente do perí odo que transcorre entre a abertura da sucessão e a instauração do inventário, com o compromisso do inventariante, estabelecendo modos de administrá-la, segundo as normas do condominio, pelo cônjuge supérstite, pelo herdeiro que estiver na posse dos bens, pelo testamenteiro ou por pessoa de confiança do juiz, com o objetivo de assegurar a sua integralidade até a partlha e entrega dos quinhões hereditários aos herdeiros (arts. 1.791, parágr. único e 1.797), situação essa não muito bem definida no estatuto vigente.

Propõe o Projeto alterações na ordem da vocação hereditária, para incluir o cônjuge sobrevivente como herdeiro necessário (art. $1.829)$, se ao tempo da morte não estava do outro separado judicialmente ou de fato, há mais de dois anos (art. 1.830), hi pótese em que concorre com descendentes do falecido, cabendolhe quinhão igual ao dos descendentes por cabeça, não podendo sua quota hereditária ser inferior à quarta parte da herança, se ascendente dos herdeiros com que concorrer (art. 1.832) Também concorrerá na herança com as cendentes do falecido o cônjuge supérstite (art. 1.836) e se com ascendente de primeiro grau, tocar-lhe-á um terço da heranca, cabendo-lhe a metade do morte-mor liquido, se houver um único ascendente ou se mais afastado for o grau de parentesco afim, na linha reta ascendente (art. 1.837) Caberá ao cônjuge sobrevivente a totalida de da herança, na falta de herdeiros necessários do falecido, nas linhas descendente e ascendente (art. 1.838).
Partici pará da sucessão do outro o companheiro ou a companheira, quanto aos bens adquiridos na vigência da união estável, em condições semelhantes às do cônjuge e em similitude com o que dispõe a Lei no 8.971/94, mas na concorrência com filhos comuns (art. 1.790, "caput"), não lhe cabe a quota mínima de um quarto da herança, tal como é deferida ao cônjuge supérstite (art. 1.790, I). Concorrendo o companheiro ou a companheira com herdeiros só do autor da herança, toca-lhe a metade do couber a cada um daqueles (art. 1.790, II); se concorrer com outros parentes sucessíveis, inclusive ascendentes e colaterais, terá direito a um terço da herança (art. 1.790, III); e terá direito à totalidade do patrimônio do companheiro ou companheira falecido, se não houver parentes sucessiveis, em qualquer linha e em qualquer grau de parentesco (art. 1.790, IV).

No âmbito da sucessão testamentária, há modificações mais acentuadamente de ordem formal. Na ordem substancial, é de se salientar, entre as modalidades especiais de testamento, arroladas em "numerus clausus" (art. 1.886, "caput", apenas o acolhimento do testamento aeronáutico (arts. 1.886, II e 1.889 usque 1.891) à semelhança do testamento marítimo, que vinha sendo contemplado no nosso direito (arts. 1.886 , I e 1.890 usque 1.892), sendo conservada pelo Projeto, quanto ao testamento militar, como subespécie do mesmo, a forma nuncupativa (art. 1.896 e parágr. único).

Quanto às modalidades comuns, foram conservados pelo Projeto os testamentos público, cerrado e particular (art. 1.862), mantendo a proibição do testamento conjuntivo, seja simultâneo, recíproco ou correspectivo (art. 1.863). É de notar que a nova proposta de codificação institui modalidade simplificada de testamento particular, não prevista na codificação vigente, autorizando, em circunstâncias excepcionais, a serem declaradas na cédula, a realização de 
próprio punho desse ato de última vontade do testador, sem testemunhas, que poderá ser confirmado a critério do juiz, no ato de publicação e registro judicial do testamento (art. 1.879).

$\mathrm{Na}$ ordem formal, o Projeto simplifica, sem comprometer a validade do ato, os requisitos exigidos pela codificação de 1.916. As três modalidades de testamento comum podem ser escritas manual ou mecanicamente, esta por qualquer instrumento mecânico, inclusive por digitação, desde que todas as páginas sejam numeradas e autenticadas com a assinatura do testador ou por quem a seu rogo o escrever (arts. 1.864 e 1.868, respectivos parágrafos únicos e art. $1.876, \S 2^{\circ}$ ). Os testamentos cerrado e particular podem ser escritos em língua estrangeira, naturalmente se o testador e as testemunhas forem versadas na língua escolhida (arts. 1.871 e 1.880 )

Quanto ao número de testemunhas que devem obrigatoriamente estar presentes no ato, o Projeto as reduziu para duas, no testamento público e no cerrado, as cinco testemunhas exigidas pelo Código vigente (arts. 1.864, I e
1.868, I) e para três, pelo menos, no testamento particular (art. 1.878, $\S 1^{\circ}$ ), quando para esta modalidade são também exigidas cinco no estatuto de 1.916. Para a modalidade especial de testamento marítimo são exigidas duas testemunhas, como na codificação anterior e para a outra modalidade especial do testamento aeronáutico, ora criada, as mesmas duas testemunhas (art. 1.888), enquanto que, para a modalidade especial do testamento militar, são mantidas as duas testemunhas exigidas no estatuto anterior, ou três, se o testador não puder ou não souber assinar, caso em que assinará por ele uma das testemunhas (art. 1.893).

Aqui, nesta breve exposição, apresentada de maneira sumária por exigência de espaço no período em que será publicada traz-se a notícia dos novos institutos da or dem civil moderna, acolhidas pelo Projeto, e bem assim as principais modificações supressões dos contemplados na codificação de 1.916, com o escopo de substituí-la em sua integralidade por um novo estatuto consentâneo com as conquistas humanas, sociais, culturais e econômicas da Nação.

\section{Relações de Consumo na pós-modernidade: Em defesa de uma interpretação finalista dos Artigos 2o e 29 do $\mathrm{CDC}^{1}$}

\author{
Claudia Lima Marques
}

Professora da Universidade Federal do Rio Grande do Sul, Doutora em Direito pela Universidade de Heidelberg, Alemanha. Mestre em Direito pela Universidade de Tübingen e Especialista em Integração Européia pelo Europa-Institut, Saarbrücken, Alemanha
INTRODUÇÃO

Neste belo encontro sobre os Desafios do direito atual, gostaria de aprofundar a análise do campo de aplicação do $\mathrm{CDC},{ }^{2}$ concentrando-me em dois aspectos ainda polêmicos das relaçōes de consumo e que me parecem decisivos na prática: no campo de aplicação subjetivo do CDC, a ainda viva discussão sobre o sujeito de direito consumidor, e, em especial, so- bre quais os critérios usados para a identificação deste sujeito tutelado na doutrina e na jurisprudência, mister, pois, analisar este novo sujeito pós-moderno de direitos, o consumidor, destacar sua pluralidade, fluidez e finalismo impostos pela técnica do CDC, propondo critérios, ao mesmo tempo, atualizados e sólidos para sua identificação nas relçaões de consumo (Parte $I)^{3}$ e, no campo de aplicação material do CDC, útil parece-me uma reflexão mais detida sobre
Versão atualizada da palestra apresentada no Seminário "Desafios do Direito Contemporâneo" do Mestrado em Direito da Faculdade de Campos (RJ), 1999. A autora agradece à Profa. Dra. Rosangêla Lunardelli Cavallazzi e ao Prof. Dr. Gustavo Tepedino as instigantes discussóes sobre o tema e o agradável e estimulante trabalho conjunto na cadeira "Relaçôes de consumo" no Mestrado Acadêmico de Campos.

2 Em meu artigo, "Proposta de uma teoria geral dos serviços com base no Código de Defesa do Consumidor - A evolução das obrigações envolvendo serviços remunerados direta ou indiretamente", publicada em Revista Direito do Consumidor, vol. 33 (2000), p. 79 a 122, analisei as relaçóes de consumo, com especial Revista Direito do Consumidor, vol. 33 (200), $p .79$ a 122 , analisei as relaçóes de consumo, com especial
ênfase nas prestaçóes envolvendo de servicos, analisando seus elementos intrínsecos, a nova noção de obrigação, total e cooperativa, a idéia de vinculação própria por atos pré-negociais e os seus elementos externos, os sujeitos (consumidor e fornecedor), o objeto, e a finalidade destas relaçóes de consumo como reguladas pelo Código de Defesa do Consumidor.

3 Esta parte da exposição será desenvolvida também para o V Congresso Brasileiro de Direito do Consumidor, a acontecer em Belo Horizonte, de 2a 5 de maio, a ser publicada em seus anais como título: 'Direitos básicos do consumidor na sociedade pós-moderna de serviços: o aparecimento de um sujeito novo e a realização de seus direitos", ainda inédito.

Revista da Faculdade de Direito da UFRGS, v. 19, Março/2001 